\title{
Um novo modelo de isolamento do tumor de Walker utilizando o gradiente de Ficoll-Hypaque ${ }^{1}$
}

\author{
A novel model for isolation of Walker's tumoral \\ cells using the Ficoll-Hypaque gradient
}

\begin{abstract}
Sônia Leite Silva ${ }^{2}$, Silvia Fernandes Ribeiro Silva ${ }^{3}$, Italo Nascimento Farias ${ }^{4}$, Rosa Salani Mota ${ }^{5}$, Maria Elisabete Moraes $^{6}$, Henry de Holanda Campos ${ }^{7}$, Francisco Valdeci Ferreira ${ }^{8}$, Manoel Odorico Moraes Filho ${ }^{9}$

1. Trabalho realizado no Laboratório de Cirurgia Experimental do Departamento de Fisiologia e Farmacologia - Unidade de Farmacologia Clínica da Universidade Federal do Ceará - UFC, Fortaleza-CE, Brasil.

2. Doutora, Professora Adjunto da Disciplina de Fisiologia Humana da Universidade de Fortaleza-UNIFOR e Médica da Unidade de Nefrologia e Transplante Renal da UFC, Brasil.

3. Mestre, Professora Assistente da Disciplina de Imunologia da UNIFOR e Diretora do Laboratório de Histocompatibilidade e Imunologia de Transplantes do Centro de Pesquisas em Doenças Hepato-Renais da UFC, Brasil.

4. Farmacêutico Bioquímico Graduado pela UNIFOR, Brasil.

5. Mestre e Professora Adjunto da Disciplina de Bioestatística da UFC, Brasil.

6. Doutora, Professora Adjunto da Disciplina de Farmacologia Básica e Clínica da UFC e Coordenadora da Unidade de Farmacologia Clínica da UFC, Brasil.

7. Doutor, Professor Titular da Disciplina de Medicina Interna e Diretor da Faculdade de Medicina da UFC, Brasil.

8. Doutor e Chefe do Laboratório de Patologia do Instituto do Câncer do Ceará, Brasil.

9. Doutor e Professor Adjunto da Disciplina de Farmacologia Básica e Clínica da UFC, Brasil.
\end{abstract}

\section{RESUMO}

Objetivo: Analisar uma nova técnica de isolamento das células do tumor de Walker, utilizando o gradiente de ficollhypaque. Métodos: Vinte ratos Wistar machos foram divididos em 2 grupos (G1, G2). O tumor do animal doador foi dissecado, triturado em solução de ringer lactato e filtrado. A suspensão celular obtida foi dividida em duas alíquotas (A1 e A2) e a alíquota A2 foi centrifugada em gradiente de ficoll-hypaque. As duas alíquotas foram ajustadas para uma concentração de 1 X $10^{6}$ células/ml. Um ml da suspensão A1 ou A2 foi injetado por via subcutânea na axila direita dos ratos dos seus respectivos grupos. Os diâmetros tumorais, peso tumoral e análise histológica foram avaliados. Resultados: Não houve diferença no volume tumoral $\left(\mathrm{G} 1=17,9 \pm 3,8 \mathrm{~cm}^{3} ; \mathrm{G} 2=17,2 \pm 4,4 \mathrm{~cm}^{3} ; \mathrm{p}=0,190\right)$ e no peso tumoral $(\mathrm{G} 1=7,0 \pm 1,8 \mathrm{~g}$;

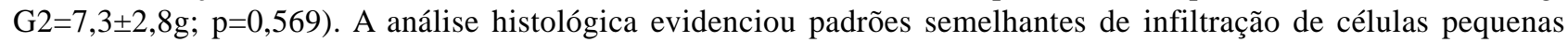
indiferenciadas e de necrose nos dois grupos. Entretanto, exsudato granulocítico leve a moderado foi mais acentuado no G2 do que no grupo G1 e hemorragia leve a moderada foi observada somente no grupo com ficoll. Conclusão: O gradiente de ficoll-hypaque é uma técnica adequada de isolamento das células do tumor de Walker e fornece uma suspensão celular menos contaminada com outros tipos celulares.

Descritores: Carcinoma 256 de Walker. Modelos Animais. Neoplasias Experimentais. Ratos.

\begin{abstract}
Purpose: The purpose was to evaluate a novel technique for isolation of Walker's tumoral cells using a Ficoll-Hypaque gradient and its further influence on tumor development. Methods: Twenty male Wistar rats have been divided in 2 groups: G1= without ficoll, G2= with ficoll. Tumor was excised, homogenized and suspended in lactate ringer. A sample of the cell suspension was adjusted at a concentration of $1 \mathrm{X} 10^{6}$ cells/ml (G1). A second sample was centrifuged on a Ficoll-Hypaque gradient and the cell concentration was then adjusted (G2). Tumor was implanted by subcutaneous injection of $1.0 \mathrm{ml}$ in the right armpit of rats. Tumor volume (TV) and tumor weight (TW) were compared in two groups. Results: There were no differences between the two groups in TV $\left(\mathrm{G} 1=17.9 \pm 3.8 \mathrm{~cm}^{3}\right.$ vs. $\left.\mathrm{G} 2=17.2 \pm 4.4 \mathrm{~cm}^{3} ; \mathrm{p}=0.190\right)$ and $\mathrm{TW}(\mathrm{G} 1=7.0 \pm 1.8 \mathrm{~g}$ vs. $\mathrm{G} 2=7.3 \pm 2.8 \mathrm{~g} ; \mathrm{p}=0.569$ ). The histological analysis showed similar patterns of infiltration by small-undifferentiated cells and necrosis in both groups. However, a mild to moderate granulocytic exsudate was more frequent in the animals whose tumors derived from Ficoll-isolated cells. Hemorrhage from slight to moderate was only observed in this group. Conclusion: A Ficoll-Hypaque gradient can provide more adequate isolation of Walker's tumor and the cell suspension obtained by this technique has lower contamination by other cell types.
\end{abstract}

Key words: Carcinoma 256, Walker. Animal, Models. Neoplasms, Experimental. Rats. 


\section{Introdução}

O tumor de Walker foi descrito pela primeira vez, em 1928, por George Walker, como uma massa tumoral na glândula mamária de uma rata albina prenha, que regrediu temporariamente durante o período de lactação. O exame histopatológico revelou um adenocarcinoma. O tumor foi transplantado para outros ratos albinos com índice de pega de $56 \% .^{1}$ Este tipo de tumor pode ser perpetuado através das mais variadas técnicas. Walker realizou, pela primeira vez, o transplante usando fragmentos do tecido tumoral. Posteriormente, diversos pesquisadores inocularam, por via intramuscular, suspensões tumorais obtidas da forma sólida do tumor com desenvolvimento tumoral bem sucedido. Outras formas de obtenção das células do tumor de Walker têm sido utilizadas, como a cultura in vitro ${ }^{1}$ e a forma ascítica. ${ }^{2}$

Após sucessivos implantes, a neoplasia apresentou variações morfológicas, assumindo formas carcinomatosa, sarcomatosa mista e carcinossarcomatosa. ${ }^{3}$ Metástase após inoculação do tumor de Walker, por via intramuscular, tem sido observada nos rins, baço, pulmões, fígado, supra-renais, medula-óssea, coração e língua. ${ }^{4}$

Nós propomos uma nova técnica de isolamento das células do carcinossarcoma 256 de Walker, usando o modelo in vivo, que permite a obtenção de uma suspensão celular com maior grau de pureza.

\section{Métodos}

Foram utilizados 20 ratos machos da linhagem Wistar, com quatro a oito semanas de vida, pesando entre 124 e 180 g, fornecidos pelo Biotério da Universidade Federal do Ceará, mantidos em gaiolas com no máximo 5 animais, com água mineral (Indaiá ${ }^{\circledR}$ ) e ração comercial (Biobase Nutrição Animal®) ad libitum. Durante o período experimental os animais foram mantidos em condições padrões de temperatura e ciclo claro/escuro.

Os animais foram divididos aleatoriamante em dois grupos, de acordo com a utilização ou não do gradiente de ficoll-hypaque para isolamento das células do tumor de Walker: grupo 1= sem ficoll (G1); grupo 2= com ficoll (G2). Para obtenção da suspensão tumoral foram utilizados cinco ratos machos da linhagem Wistar como doadores do tumor de Walker fornecidos pelo Biotério da Universidade Federal do Ceará, mantidos nas mesmas condições dos animais do experimento.

Este trabalho foi aprovado pela Comissão de Ética em Pesquisa Animal (CEPA) da Universidade Federal do Ceará e todos os experimentos foram realizados segundo os Princípios Éticos utilizados na Experimentação Animal adotados pelo Colégio Brasileiro de Experimentação Animal (COBEA).

\section{Obtenção da suspensão celular dos animais doadores}

Um ml de células obtidas do tumor de Walker na concentração de 1×10\% /células/ml foi inoculada por via intramuscular na coxa direita dos cinco ratos doadores, após leve sedação com éter sulfúrico. No $7^{\circ}$ dia após o implante tumoral, os ratos foram anestesiados com xilazina $(10 \mathrm{mg} / \mathrm{kg})$ e cetamina $(90 \mathrm{mg} / \mathrm{kg})$ e sacrificados por deslocamento cervical. A coxa foi dissecada utilizando material esterilizado e os fragmentos tumorais, isentos de tecido necrótico, foram retirados, triturados e colocados em placa de Petri, contendo solução de gentamicina a $0,45 \%$ e Ringer com lactato na proporção de 1:10 para obtenção da suspensão celular. A suspensão celular, assim obtida, foi filtrada e homogeneizada. Uma gota desta suspensão foi colocada em câmara de Newbauer e corada com azul de tripano para avaliar a viabilidade celular. Em seguida, a suspensão celular foi ajustada em câmara de Newbauer para manter uma concentração de $1 \times 10^{6}$ células tumorais/mL. Após o ajuste da concentração, a suspensão celular foi dividida em duas alíquotas (A1 e A2) acondicionadas em tubos falcon de $50 \mathrm{ml}$ e guardadas a $4^{\circ}$ até o momento do uso. A alíquota A2 foi utilizada posteriormente para obtenção da suspensão celular após centrifugação em gradiente de Ficoll-hypaque.

\section{Preparo da suspensão celular em Ficoll-hypaque}

A alíquota A2 foi colocada em tubos de Fisher de $1 \mathrm{~mL}$ contendo $0,2 \mathrm{~mL}$ de Ficoll-Hypaque, com cuidado para que a suspensão celular fique sobre o FicollHypaque. Os tubos foram centrifugados a 5.500gpm durante 3 minutos. Após a centrifugação, o anel de células formado sobre o Ficoll foi retirado com pipeta Pasteur e colocado em novos tubos de Fisher. Em seguida, foi adicionado solução de gentamicina e Ringer com lactato nos tubos contendo o anel de células e, os mesmos foram centrifugados a $1.000 \mathrm{gpm}$ durante 1 minuto. O sobrenadante foi descartado e o sedimento celular ressuspenso com a solução de gentamicina e Ringer com lactato e a suspensão celular novamente foi centrifugada a 1.000 gpm durante 1 minuto. Este procedimento foi repetido mais uma vez e o sedimento celular obtido foi ressuspenso com solução de gentamicina e Ringer com lactato. A viabilidade celular e a concentração celular da suspensão foram determinadas da mesma forma que a suspensão celular obtida dos animais doadores. A Figura 1 mostra o aspecto citológico da suspensão celular obtida utilizando (alíquota A2) ou não o gradiente de Ficoll-hypaque (alíquota A1). 


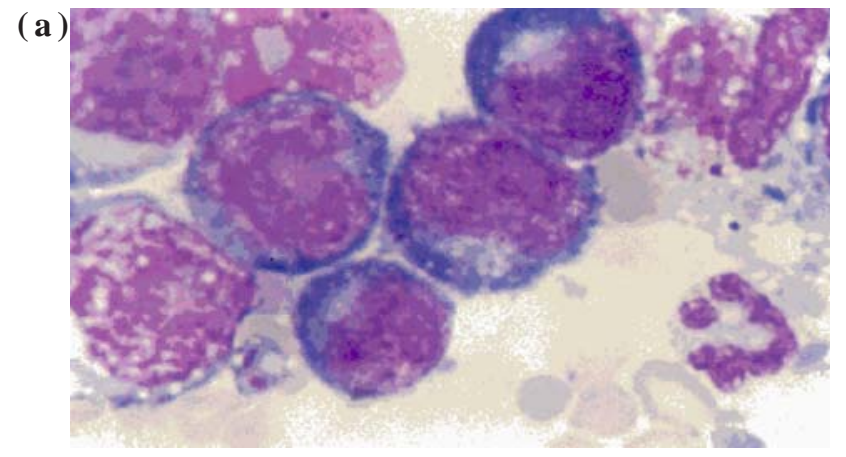

(b)

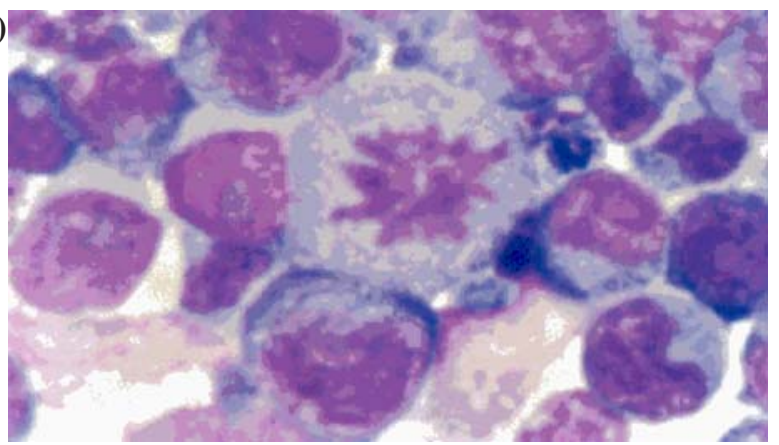

FIGURA 1 - Esfregaço de células do carcinossarcoma 256 de Walker coradas com hematoxilina e eosina: suspensão celular obtida a partir de tecido tumoral fragmentado, homogeneizado em solução de ringer com lactato e gentamicina, filtrado e centrifugado com (a) e sem (b) gradiente de ficoll-hypaque

\section{Experimento}

Os 20 animais, divididos em 2 grupos (G1 e G2) com dez animais cada um, foram levemente sedados com éter sulfúrico para a inoculação da suspensão celular. Todos os animais do grupo G1 foram inoculados com 1ml da suspensão celular obtida sem a utilização do Ficoll-hypaque (alíquota A1) na concentração de $1 \times 10^{6}$ células $/ \mathrm{mL}$, por via subcutânea, na região dorsal do animal, utilizando seringa de insulina, enquanto que, os animais do grupo 2 foram inoculados com a suspensão celular contida na alíquota A2 obtida utilizando gradiente de Ficoll-hypaque.

A medida do tumor foi realizada diariamente utilizando-se um paquímetro manual. O cálculo da curva de crescimento tumoral foi baseado na fórmula de Steel $(1977)^{4}: \mathrm{V}\left(\mathrm{cm}^{3}\right)=\mathrm{D} \mathrm{x} \mathrm{d}{ }^{2}$ / 2, onde, $\mathrm{V}=$ volume tumoral, $\mathrm{D}=$ maior diâmetro tumoral, $\mathrm{d}=$ menor diâmetro tumoral. O peso corporal dos animais foi mensurado a cada três dias.

No $10^{\circ}$ dia do experimento, os animais foram anestesiados com xilazina e cetamina e sacrificados por exsangüinação. Todos os animais sacrificados foram necropsiados para análise macroscópica e pesquisa de metástases no fígado, baço, pulmão. O tumor foi dissecado, pesado e, em seguida, fixado em formol a $10 \%$, incluídos em parafina, cortado no micrótomo na espessura de 4 a $6 \mathrm{~m}$, corado pela técnica de hematoxilinaeosina e analisado em microscópica óptica. Os parâmetros analisados foram: infiltração de pequenas células neoplásicas indiferenciadas (NIPC), necrose tecidual, infiltração de células granulocíticas e áreas de hemorragia. Cada parâmetro foi avaliado por um observador cego e quantificado como leve $(+)$, moderado $(++)$ ou intenso $(+++)$, de acordo com o número de focos de hemorragia ou necrose.

\section{Análise estatística}

Os valores foram expressos como média \pm desvio padrão. As análises estatísticas foram realizadas utilizando o programa de computação SPSS Data Editor software (SPSS for Windows software). Os resultados foram considerados significativos quando $\mathrm{p}<0,05$. Para comparação dos grupos foi empregado o teste ANOVA para modelos multivariados e para modelos com análise de medidas repetidas ao longo do tempo foi utilizado o teste de Tukey.

\section{Resultados}

O crescimento tumoral foi observado em todos os animais implantados, independente da técnica utilizada. Não houve diferença significativa no volume tumoral entre as duas técnicas ao longo do tempo. No $10^{\circ}$ dia o volume tumoral foi de 17,9 \pm $3,8 \mathrm{~cm}^{3}$ para o grupo sem ficoll e de $17,2 \pm 4,4 \mathrm{~cm}^{3}$ para o grupo com ficoll ( $\mathrm{p}=0,190$, Figuras $2 \mathrm{e} 3)$.

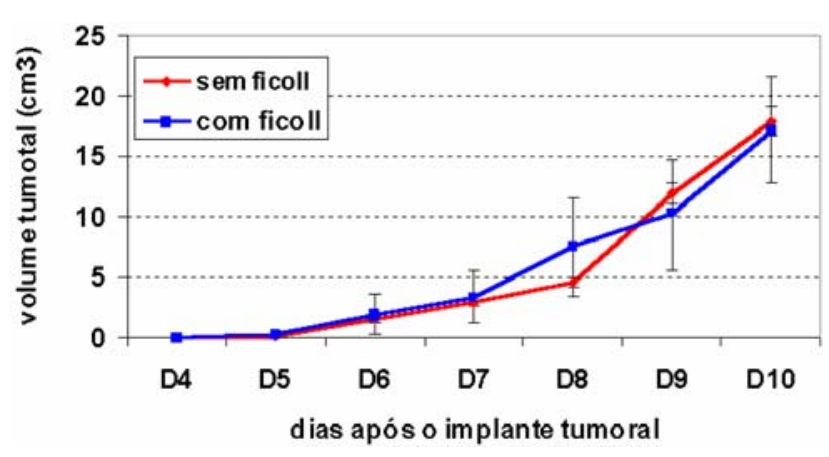

FIGURA 2 - Crescimento tumoral em animais inoculados com carcinossarcoma 256 de Walker, utilizando células tumorais isoladas com e sem gradiente de Ficoll-Hypaque.* Não houve diferença significativa entre os dois grupos ao longo do experimento $(\mathrm{p}=0,190)$.

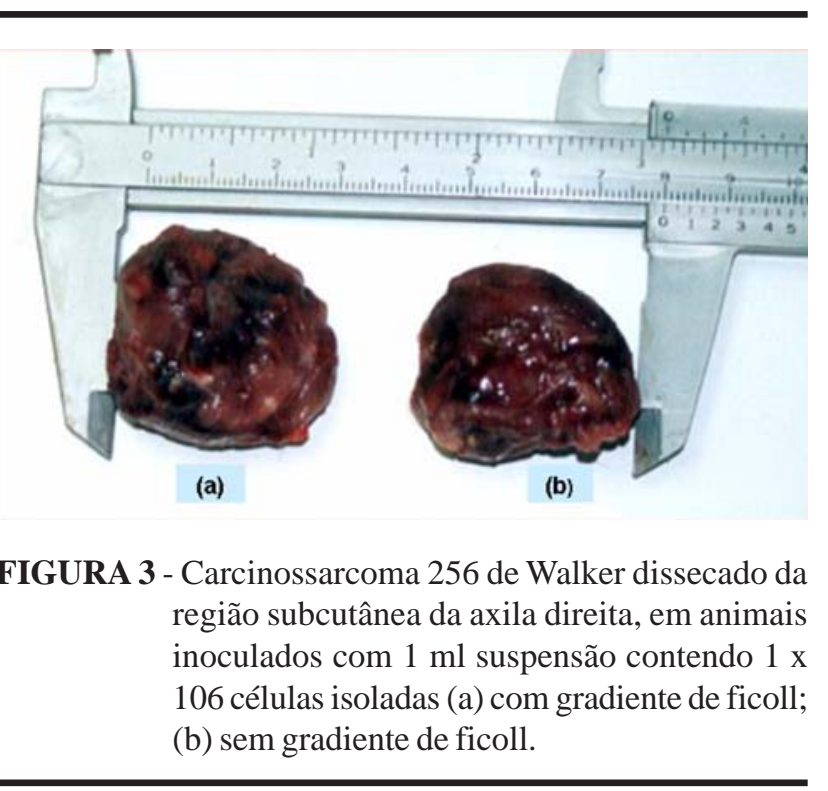


Não houve diferença significativa $(p=0,569)$ no peso tumoral entre os dois grupos: sem ficoll, 7,0 \pm 1,8 g; com ficoll, 7,3 $\pm 2,8 \mathrm{~g}$. A Figura 4 mostra as alterações histológicas evidenciadas no carcinossarcoma 256 de Walker. A análise histológica evidenciou padrões semelhantes de intensidade de infiltração de células pequenas indiferenciadas e de necrose nos dois grupos. Entretanto, exsudato granulocítico leve a moderado foi mais acentuado no grupo com ficoll (100\%) do que no grupo sem ficoll (80\%) e hemorragia leve
(50\%) a moderada (37,5\%) foi observada somente no grupo com ficoll. (Tabela 1). O peso corporal dos animais foi semelhante nos dois grupos (sem ficoll, 157,9 \pm 19,5 g; com ficoll, 157,4 $\pm 17,5 \mathrm{~g}$ ). Todos ganharam peso ao longo do estudo, não havendo diferença entre eles ao final do experimento (sem ficoll, 176,4 \pm 25,7 g; com ficoll, 177,9 \pm 27,0 g; $\mathrm{p}=0,106)$. Não foi observada metástase tumoral em nenhum animal dos dois grupos.
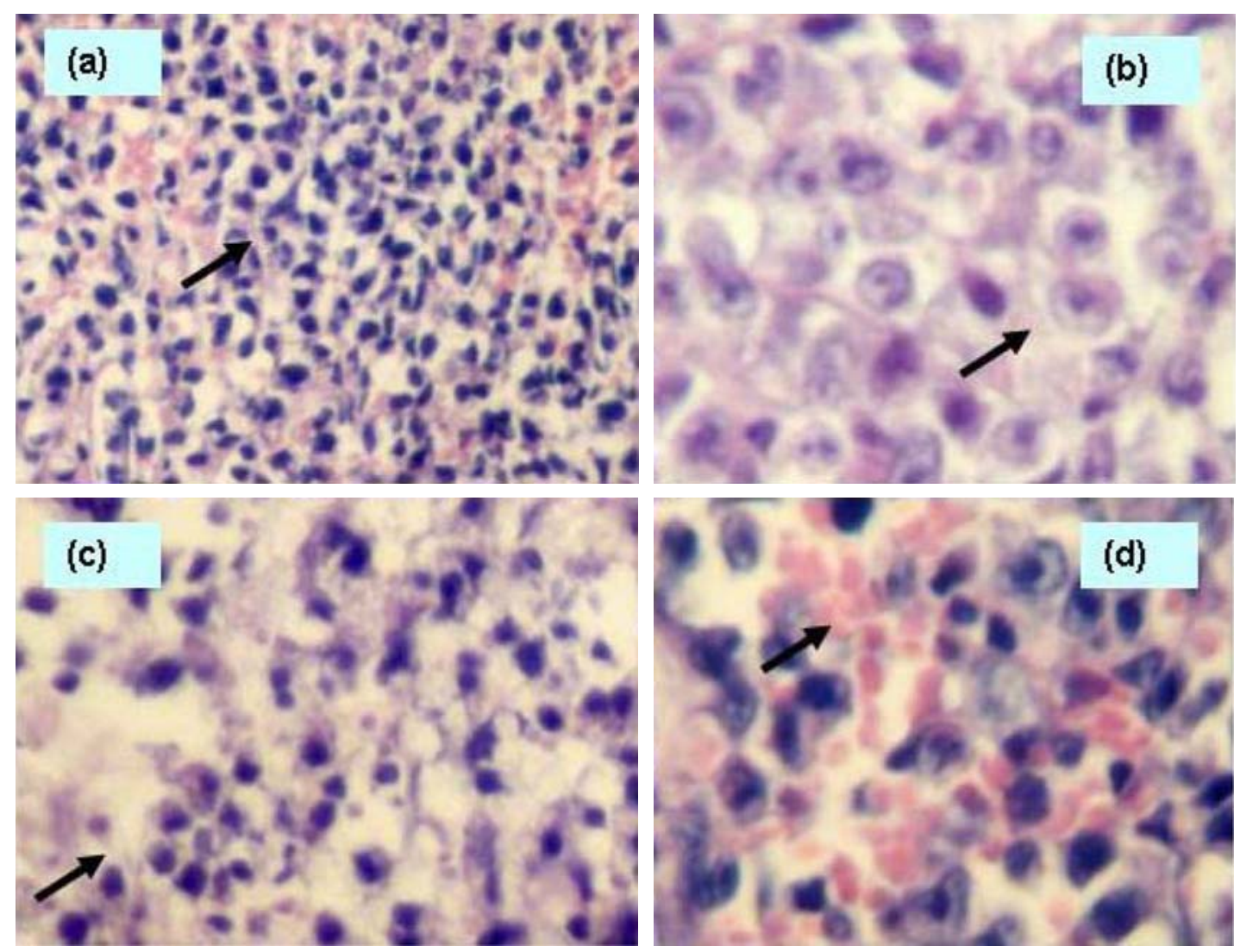

FIGURA 4 - Cortes histológicos de carcinossarcoma 256 de Walker, dissecado da região subcutânea da axila direita de ratos Wistar, mostrando (a) a presença de neoplasia indiferenciada de pequenas células com aspecto denso; (b) pseudonucleado; (c) áreas de necrose, reabsorção, edema; (d) hemorragia intersticial (aumento de 200 e 400 X). Célula tumoral isolada pela técnica padrão (sem gradiente de ficoll-hypaque).

TABELA 1 - Análise histológica do tumor de Walker no $10^{\circ}$ dia após o implante em ratos Wistar, utilizando suspensão celular obtida com ou sem o gradiente de Ficoll-Hypaque.

\begin{tabular}{llll}
\hline & Parâmetros & $\begin{array}{l}\text { Sem ficoll } \\
(\mathbf{n = 1 0 )}\end{array}$ & $\begin{array}{l}\text { Com ficoll } \\
(\mathbf{n = 1 0})\end{array}$ \\
\hline \multirow{2}{*}{ NIPC } & Leve & $40 \%$ & $14 \%$ \\
& moderado & $50 \%$ & $86 \%$ \\
\hline \multirow{2}{*}{ Necrose } & intenso & $10 \%$ & - \\
& Leve & $40 \%$ & $37,5 \%$ \\
& moderado & $50 \%$ & $50 \%$ \\
Exsudato granulocítico & intenso & $10 \%$ & $12,5 \%$ \\
& Leve & $60 \%$ & $87,5 \%$ \\
& moderado & $20 \%$ & $12,5 \%$ \\
\hline \multirow{2}{*}{ Hemorragia } & intenso & - & - \\
& Leve & - & $37,5 \%$ \\
\hline
\end{tabular}

NIPC = neoplasia indiferenciada de pequenas células 


\section{Discussão}

O carcinossarcoma 256 de Walker é um modelo de neoplasia freqüentemente utilizado para estudar o efeito de agentes citotóxicos ${ }^{6} \mathrm{e}$ imunossupressores ${ }^{7}$ por se tratar de um modelo bem caracterizado, facilmente mantido em laboratório, de crescimento rápido e uniforme, que raramente apresenta regressão espontânea e tem índice de "pega" de $100 \%$ em ratos Wistar inoculados por via intramuscular. ${ }^{8,9} \mathrm{~A}$ suspensão desta célula tumoral tem sido utilizada em diversos modelos experimentais, como na implantação do tumor no lobo inferior do pulmão direito ${ }^{10}$ e no estômago. ${ }^{11}$ A suspensão celular utilizada para inoculação em animais experimentais pode ser obtida a partir de células de tumor implantado por via intraperitoneal ou intramuscular. Diversas técnicas de isolamento das células tumorais têm sido utilizadas: a) a partir de líquido ascítico, b) tumor sólido fragmentado, c) tumor sólido fragmentado e coado e d) tumor sólido fragmentado, centrifugado e coado. No Laboratório de Cirurgia Experimental da Universidade Federal do Ceará, o tumor de Walker tem sido mantido através da inoculação da suspensão tumoral por via intramuscular na coxa de ratos Wistar. A suspensão tumoral é habitualmente obtida através da fragmentação e filtração do tumor sólido. Como nas técnicas descritas acima, a suspensão celular obtida com esta técnica é formada de células tumorais, células sangüíneas, de macrófagos na forma ascítica e pequenos fragmentos de tecidos, que serão posteriormente injetados no animal experimental. $\mathrm{O}$ gradiente de ficoll hypaque permite a separação destes componentes baseada no campo gravitacional e na gravidade específica. O conteúdo de água e a quantidade de lipídeos nas membranas celulares determinam a gravidade específica de uma suspensão celular. Os eritrócitos, cujo conteúdo de água é de 60 a $70 \%$ devido ao seu alto teor de hemoglobina, tem uma gravidade específica elevada. Assim, os elementos podem ser isolados: eritrócitos (1085-1115), granulócitos (1080-1190), linfócitos (1070-1080), monócitos (1065-1075), plaquetas (1025-1035). ${ }^{11}$ A solução de ficollhypaque é o gradiente de densidade mais utilizado para isolar células mononucleares. O ficoll é um polímero de sacarose de alto peso molecular e o hypaque (ou isopaque) é um composto orgânico iodado. Como um meio de separação, o ficoll aumenta a viscosidade promovendo a formação de rouleaux dos eritrócitos e o hypaque aumenta a densidade do meio. Quando apropriadamente misturado e com densidade de 1077 em temperatura ambiente, o ficoll-hypaque é mais denso que as células mononucleares e as plaquetas. Com o uso de centrifugação, os granulócitos, eritrócitos e os monócitos carregados de ferro ficarão depositados no tubo de centrifugação. ${ }^{12}$ No nosso estudo o gradiente permitiu preparar uma suspensão tumoral isenta de hemácias, granulócitos, plaquetas e pequenos fragmentos de tecidos, que permaneceram na suspensão padrão mesmo após a filtração da suspensão. $\mathrm{O}$ grande inconveniente do ficoll-hypaque, além de seu custo, é a citotoxicidade. Entretanto, a viabilidade celular não foi comprometida, conforme constatado pelo azul trypano, provavelmente devido à cuidadosa lavagem da suspensão celular visando à retirada do ficoll-hypaque após o isolamento celular. Além do mais, o crescimento tumoral nos animais implantados com células isoladas usando a nova técnica foi semelhante àqueles implantados com a suspensão celular usando a técnica padrão. Entretanto, a análise histológica mostrou maior infiltração granulocítica e hemorragia nos tumores do grupo com ficoll. Este achado pode sugerir que a utilização de uma suspensão tumoral desprovida de contaminantes celulares de alguma forma alterou a resposta inflamatória do hospedeiro ao tumor. Esta nova técnica de isolamento do carcinossarcoma 256 de Walker poderá ser utilizada nos protocolos que estudam a participação de mecanismos inflamatórios no crescimento e desenvolvimento tumoral, devido a menor interferência de contaminantes celulares.

\section{Referências}

1. Earle WR. A study of the Walker rat mammary carcinoma 256, in vivo and in vitro. Am J Cancer. 1935; 24: 566-612.

2. Agostinho D, Cliffton EE. The growth and transplantability of the carcinosarcoma of Walker 256 in the ascitic form. Experientia. 1968; 24: 166-7.

3. Fisher ER, Fisher B. Electron microscopic, histologic and histoquemical features of the Walker carcinoma. Cancer Res. 1961; 21: 527-31.

4. Stell GG. Growth kinetics of tumors-cell population kinetics in relation to the growth and treatment of cancer. Oxford: Claredon; 1977.

5. Iwana de Mattos MCF, Montenegro MR, Silva CRV. Walker 256 carcinossarcoma: pathologic microscopic and ultrastructural features of the tumoral circulating cells. Ciênc Cult. 1980; 32: 849-57.

6. Smith GM. A comparison of the effects of cytotoxic agents on the Walker 256 tumor growing in the rat and at the hamster cheek pouch. Br J Cancer. 1969; 23: 88-94.

7. Silva SL, Silva SFR, Farias I, Mota RS, Carvalho RA, Moraes MO, Moraes ME, CAMPOS HH. Rapamycin even when combined with cyclosporine attenuates tumor growth but dos not induce regression of established Walker sarcomas. Transplant Proc. 2004; 36: 934-7.

8. Fonteles MC, Craveiro AA, Matos FJA, Alencar JW, Moraes MO, Medeiros MTG. Avaliação da atividade antitumoral de óleos essenciais do nordeste brasileiro. Ciênc Cult. 1978; 30: 456.

9. Moraes MO, Fonteles MC, Matos FJA, Moraes MEA. Atividade antitumoral de plantas do Nordeste do Brasil. Ciênc Cult. 1980; 32: 776-7.

10.Gomes-Neto A, Pessoa BBGP, Aguiar SA, Furtado BM, Moraes MO, Ribeiro RA. Modelo de tumor de pulmão em rato com o carcinossarcoma 256 de Walker. Acta Cir Bras. 2002; 17: 12-22.

11.Oliveira FPM, Henriques IA, Rodrigues-Filho F, Almeida PRC, Moraes MO. Estabelecimento de um modelo de tumor experimental pela inoculação do tumor de Walker em estômago de rato. Acta Cir Bras. 1988; 13: 242-7.

12.Rodey EG. Principles of histocompatibility testing methods. In: HLA Introduction to human histocompatibility. 2ed. Durango-CO: De Novo Inc; 2000. p 43-65.

\section{Correspondência:}

Sônia Leite da Silva

Rua Arquiteto Reginaldo Rangel, 55/801

60.191250 Fortaleza - CE Brasil

sonials@unifor.br
Conflito de interesse: nenhum Fonte de financiamento: nenhuma

Recebimento: 04/10/2005

Revisão: 08/11/2005

Aprovação: 05/12/2005

\section{Como citar este artigo:}

Silva SL, Silva SFR, Farias IN, Mota RS, Moraes ME, Campos HH, Ferreira FV, Moraes Filho MO. Um novo modelo de isolamento do tumor de Walker utilizando o gradiente de Ficoll-Hypaque. Acta Cir Bras. [periódico na Internet] 2006 Mar-Abr;21(2). Disponível em URL: http://www.scielo.br/acb

Figuras coloridas disponíveis em www.scielo.br/acb 